\title{
Green Fabrication of Copper Nanoparticles Dispersed in Walnut Oil Using Laser Ablation Technique
}

\author{
Amir Reza Sadrolhosseini, ${ }^{1}$ Suraya Abdul Rashid, ${ }^{1}$ Azmi Zakaria, ${ }^{2}$ and Kamyar Shameli ${ }^{3}$ \\ ${ }^{1}$ Materials Processing and Technology Laboratory (MPTL), Nanomaterials and Nanotechnology Group, \\ Institute of Advanced Technology, Universiti Putra Malaysia (UPM), 43400 Serdang, Selangor, Malaysia \\ ${ }^{2}$ Department of Physics, Faculty of Science, Universiti Putra Malaysia (UPM), 43400 Serdang, Malaysia \\ ${ }^{3}$ Malaysia-Japan International Institute of Technology (MJIT), Universiti Teknologi Malaysia, 54100 Kuala Lumpur, Malaysia
}

Correspondence should be addressed to Amir Reza Sadrolhosseini; amir17984818@gmail.com

and Suraya Abdul Rashid; suraya_ar@upm.edu.my

Received 23 November 2015; Revised 1 February 2016; Accepted 9 February 2016

Academic Editor: Nathan C. Lindquist

Copyright @ 2016 Amir Reza Sadrolhosseini et al. This is an open access article distributed under the Creative Commons Attribution License, which permits unrestricted use, distribution, and reproduction in any medium, provided the original work is properly cited.

\begin{abstract}
Synthesis of copper nanoparticles was achieved by laser irradiation of copper plate in walnut oil. The copper plate was irradiated using Nd:YAG pulse laser at different ablation time from 5 to 50 minutes, and the prepared samples were characterized using analytical methods to find the optical absorption, morphology, particle size, and capping of copper nanoparticles with walnut oil. Consequently, the absorption peak appeared at about $615,606,588,576$, and $561 \mathrm{~nm}$; and the nanoparticles formed in spherical shape in walnut oil. The particle size varied from 25 to $4.01 \mathrm{~nm}$, and the tail of the carbonyl band capped the copper nanoparticles through the electron transfer from the carboxylic group to copper nanoparticles. The refractive indices of the nanofluid were measured using a surface plasmon resonance technique and changed from $1.4691+0.008 \mathrm{i}$ to $1.4682+0.043 \mathrm{i}$ as the volume fraction increased from $0.0257 \times 10^{-5}$ to $1.26 \times 10^{-5}$. Consequently, the laser ablation method is environmentally sensitive (i.e., green) and thus is suitable for the fabrication of copper nanoparticles in walnut oil without any agent.
\end{abstract}

\section{Introduction}

Copper nanoparticles (Cu-NPs) have broad application in industry and medicine due to their physical and chemical properties [1-3]. The high electrical conductivity of $\mathrm{Cu}-$ NPs makes them suitable for applications such as modern electrical circuits, biosensors [4], and sintering additives [5]. $\mathrm{Cu}-\mathrm{NPs}$ also have other uses including anti-inflammatory [6], antioxidative [7], and antiulcer [8] application. In addition, they have been used in medicine to prevent skin photosensitivity [9] and nanoprobes. Copper nanoparticles also include considerable localized surface plasmon resonance (LSPR) in the visible region and high surface-enhanced Raman scattering.

Many methods including solution phase [10], photochemical [11], sonochemical [12], and electrochemical synthesis [13] are used to prepare and disperse copper nanoparticles in various mediums. Laser ablation introduces a green method for fabricating $\mathrm{Cu}-\mathrm{NPs}$ [14]. The preparation of $\mathrm{Cu}$ NPs in water [15], dichloromethane [16], acetonitrile [16], chloroform [16], alcohol [16, 17], and coconut oil [14] using laser ablation has been reported in the literature.

Walnut oil contains oleic (18:1), linoleic (18:2), and linolenic (18:3) acids and palmitic acid (c16:1), while concentrations of other fatty acids such as myristic acid, palmitoleic acid, eicosenoic acid, and stearic acid are very low. However, walnut oil is rich in omega-3 fatty acids, vitamins B-1, B-2, and B-3, vitamin E, and niacin, and the LDL (bad cholesterol) ratio to HDL (good cholesterol) is lower than that with other oils; hence, it is healthier and more helpful than other oils in reducing the risk of coronary artery disease [18]. Walnut oil is used in cooking and skin care because the omega-3 fatty acids it contains have high permeation in human skin and have become popular ingredients in natural skin care products [19]. 
Copper and copper nanoparticle are the mineral for healthy skin and they sometimes are used in cream and skin care spray and lotion. Therefore, in this study, the $\mathrm{Cu}-\mathrm{NPs}$ were prepared in walnut oil using laser ablation. The nanofluids are characterized using UV-visible spectrum, transmission electron microscopy (TEM), Fourier transform infrared spectroscopy (FT-IR), and atomic absorption spectroscopy (AAS) to obtain the optical absorption, particle size, morphology of nanoparticles, explanation of capping nanoparticles with walnut oil, and concentration of nanoparticles for different ablation times. Surface plasmon resonance (SPR) is an accurate method to obtain the real and imaginary parts of a refractive index. Hence, the refractive indices of walnut oil and nanofluids were measured using the SPR technique to investigate the amount of variation in the refractive index of nanofluids with different concentrations of $\mathrm{Cu}-\mathrm{NPs}$.

\section{Experimental Methods}

2.1. Synthesis of Copper Nanoparticles. The schematic diagram of the laser ablation setup is depicted in Figure 1. To prevent the formation of copper oxide, the copper plate (99.99\% purity; Sigma Aldrich, St. Louis, MO) was ablated in the presence of nitrogen gas flow [14]. The copper plate was immersed in $20 \mathrm{~mL}$ of walnut oil, and the ablation was carried out via a pulsed Q-Switched Nd:YAG laser (Brilliant) at durations of $5 \mathrm{~ns}$, a repetition rate of $10 \mathrm{~Hz}$ at wavelength of $1064 \mathrm{~nm}$. To disperse the NPs in the oil, a magnetic stirrer was used during the ablation process. The laser beam was focused on the target with a $300 \mathrm{~mm}$ focal length lens for $5,10,20,30$, and 50 minutes at room temperature with spot size about $0.7 \mathrm{~mm}$. The characterization tests of UV-visible and Fourier transform infrared spectrum (FT-IR) were conducted using UV-visible double beam photo spectrometer (Shimadzu, Columbia, MD) with a $1 \mathrm{~cm}$ optical path cell and FT-IR spectrometer (Spectrum 100, PerkinElmer). The morphology and concentration of the $\mathrm{Cu}$ NPs were determined by transmission electron microscopy (TEM, Hitachi H-7100; Hitachi, Chula Vista, CA) and atomic absorption spectroscopy (AAS, S series), respectively. The refractive indices of walnut oil and the nanofluids were measured using the surface plasmon resonance technique to discriminate variation in the refractive index for the walnut oil in the presence of different concentrations of Cu-NPs.

2.2. Surface Plasmon Resonance Setup. Surface plasmon resonance is acknowledged as the best and most accurate method for measuring the refractive index of nanomaterials. Using this approach allows for propagation of the surface plasmon waves (SPWs) on the interface between a metal layer and a dielectric medium [20]. Essentially, SPWs should be excited with a laser beam in the resonance condition. The resonance condition results from the cross-point of the dispersion curves of the surface plasmon and photon if meeting the

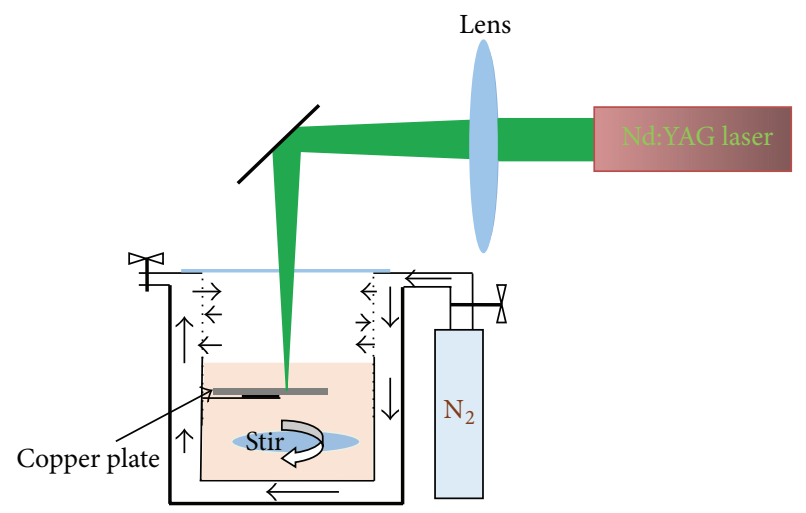

FIGURE 1: Laser ablation setup to prepare Cu-NPs in the walnut oil. The setup contains a Nd:YAG pulsed laser at wavelength $1064 \mathrm{~nm}$, a lens $(f=300 \mathrm{~mm})$, a stirrer, an insulator liquid tank, and $\mathrm{N}_{2}$ gas. The dimensions of copper plate and fluid cell were $10 \times 10 \times 3 \mathrm{~mm}$ and $20 \times 20 \times 40 \mathrm{~mm}$, respectively. The copper plate was ablated at different times such as 5, 10, 20, 30, and 50 minutes.

requirements of the energy and momentum conservation law [21], as follows:

$$
n_{p} \sin \theta=\sqrt{\frac{n_{1}^{2} n_{2}^{2}}{n_{1}^{2}+n_{2}^{2}}} .
$$

$n_{p}, n_{1}$, and $n_{2}$ are the refractive indices for the prism, metal, and dielectric, respectively, and $\theta$ is the angle of resonance. In fact, $k_{0} n_{p} \sin \theta$ is the wave number of the photon that is parallel to the interface of the mediums, and $k_{0} \sqrt{\left(n_{1}^{2} \times n_{2}^{2}\right) /\left(n_{1}^{2}+n_{2}^{2}\right)}$ is the wave number of the surface plasmon.

To obtain the resonance angle $\left(\theta_{R}\right)$ and the real $(n)$ and imaginary $(k)$ parts of the refractive index of the nanofluid, the SPR signals are analyzed by a minimization of the sum [22]:

$$
\Gamma=\sum_{\theta}\left[R_{\operatorname{Exp}}\left(\theta_{2}\right)-R_{\text {Theory }}\left(\theta_{2}\right)\right],
$$

where $R_{\operatorname{Exp}}$ and $R_{\text {Theory }}$ are the experimental and theoretical reflectance, respectively.

The SPR setup is illustrated in Figure 2. The setup consists of a precision rotation stage, a photodiode, He-Ne laser, a polarizer, lock in amplifier, and a high index prism. The rotation stage involved rotating from $45^{\circ}$ to $80^{\circ}$ and stopping for a moment to register the light intensity and angle. Then, the SPR signal was analyzed using computer software [23].

\section{Results and Discussion}

The optical absorption spectra for the pure walnut oil and the walnut oil with $\mathrm{Cu}-\mathrm{NPs}$ are presented in Figure 3. The baseline was calibrated as the reference for the pure walnut oil before the irradiation of the copper plate. As shown in Figure 3, the UV-visible peaks appeared at $615 \mathrm{~nm}, 606 \mathrm{~nm}$, $588 \mathrm{~nm}, 576 \mathrm{~nm}$, and $561 \mathrm{~nm}$ for the prepared Cu-NPs at 5 , $10,20,30$, and 50 minutes, respectively. These peaks rise 


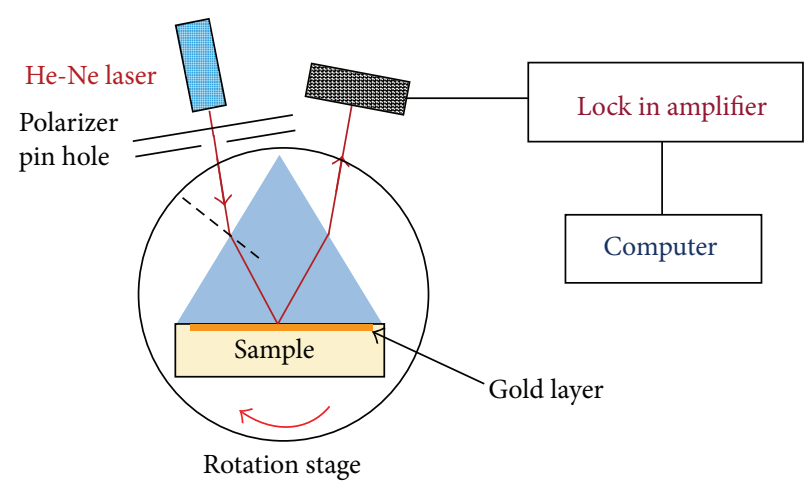

FIGURE 2: SPR setup to characterize the Cu-NPs samples. The setup consists of a photodiode, a He-Ne laser, a polarizer, a pinhole, a lock in amplifier, a rotation stage, and a high refractive index prism (ZF52).

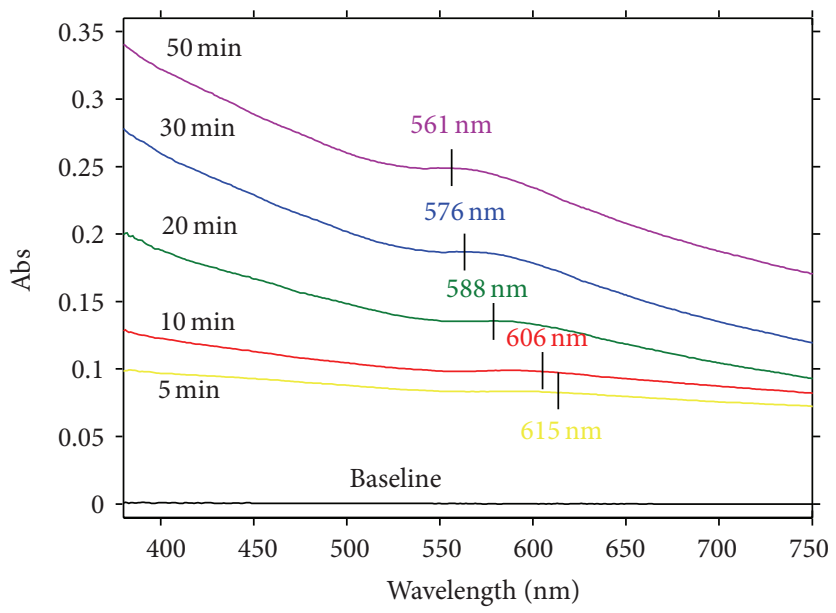

FIgURE 3: UV-visible spectra of Cu-NPs in walnut oil. The baseline is pure walnut oil, and the UV-visible peaks have blue shift from $615 \mathrm{~nm}$ to $561 \mathrm{~nm}$. So, the particle size decreases with increasing the ablation time.

from the localized surface plasmon resonance of the $\mathrm{Cu}-\mathrm{NPs}$, which allows for the formation of NPs in walnut oil and authenticates the fact that the NPs are spherical shapes. The peak intensity increased under the influence of increases in the ablation time and concentration of $\mathrm{Cu}-\mathrm{NPs}$ in walnut oil.

In addition, the concentration of $\mathrm{Cu}-\mathrm{NPs}$, measured by atomic absorption spectroscopy (AAS), increased from 2.3 to $112.6 \mathrm{mg} / \mathrm{L}$ (see Figure 4(a)); meanwhile, the volume fraction of $\mathrm{Cu}$-NPs was calculated using the following equation [14]:

$$
V=\frac{V_{p}}{V_{p}+V_{L}},
$$

where $V_{L}$ and $V_{p}$ are the volume of the walnut oil and the volume of the Cu-NPs $(m / \rho$, where $\rho$ and $m$ are the mass density of the copper and the particles mass dispersed in the walnut oil, resp.). Hence, (4) was derived from a modification and a simplification of (3) as follows:

$$
V=\frac{C_{\text {Particle }}}{C_{\text {Particle }}+\rho},
$$

where $C_{\text {Particle }}$ are the concentrations of the $\mathrm{Cu}-\mathrm{NPs}$ obtained from the AAS. Therefore, the volume fraction of nanoparticles increased as the result of an increase in ablation time from $0.0257 \times 10^{-5}$ to $1.26 \times 10^{-5}$. The pure walnut oil and nanofluid parameter values are presented in Table 1.

Figure 5 is the TEM pattern of $\mathrm{Cu}-\mathrm{NPs}$ in walnut oil. It depicts the morphology of $\mathrm{Cu}-\mathrm{NPs}$ dispersed in walnut oil which take on a spherical shape. The UTHSCSA image tool (version 3, UT Health Science Center) was used to analyze the captured images to determine the particle size. As a result, the particle size decreased from $25 \mathrm{~nm}$ to $4.01 \mathrm{~nm}$ while the ablation time and distribution of the particles increased.

At first, the $\mathrm{Cu}-\mathrm{NPs}$ formed through phase transition and nucleation; hence, crystals of the $\mathrm{Cu}$ cluster expanded from released copper atoms, and the fatty acid chain of walnut oil capped the $\mathrm{Cu}-\mathrm{NPs}$. Afterward, the laser beam interacted with the target and the nanoparticles which were released in nanofluid and the $\mathrm{Cu}-\mathrm{NPs}$ were ablated and broken to a small size (Figure 5(c)). Therefore, the particle diameter decreased as the ablation time increased (Figure 4(b)) [24].

The FT-IR spectrum analysis of nanofluids is illustrated in Figures 6(a) and 6(b). The spectra were registered at 


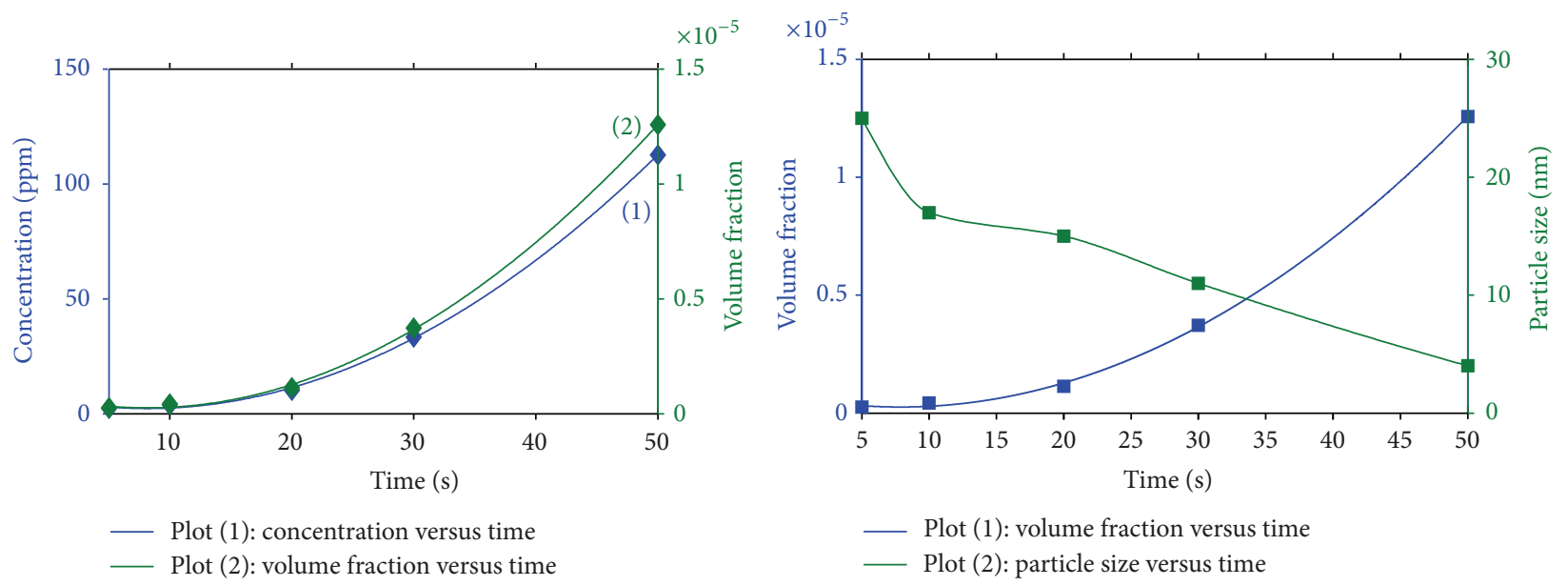

(a)

(b)

FIGURE 4: (a) Variation of nanoparticles concentration and volume fraction with ablation time. (b) Variation of volume fraction and nanoparticles size with ablation time.
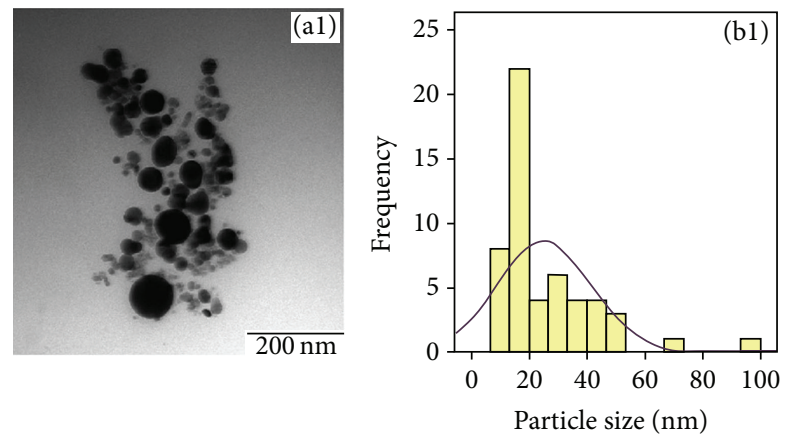

Number of particles: 53 Average of particle size: $25 \mathrm{~nm}$
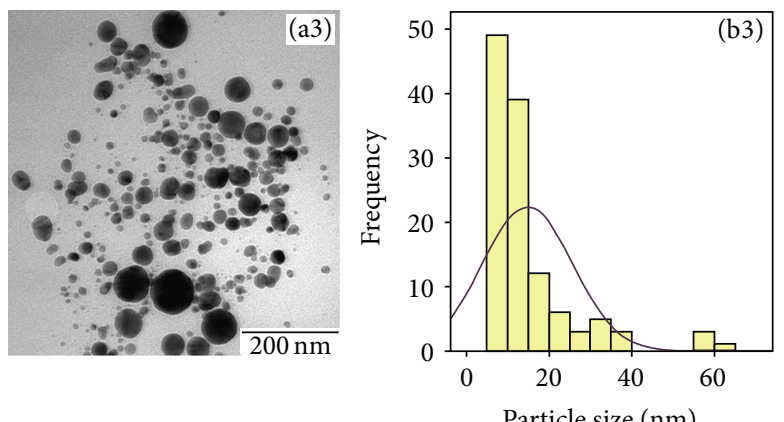

Number of particles: 121 Average of particle size: $14 \mathrm{~nm}$

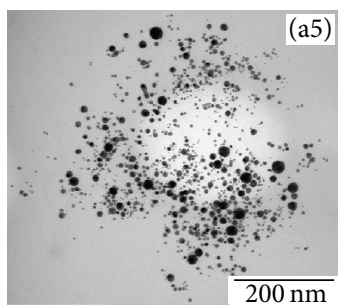

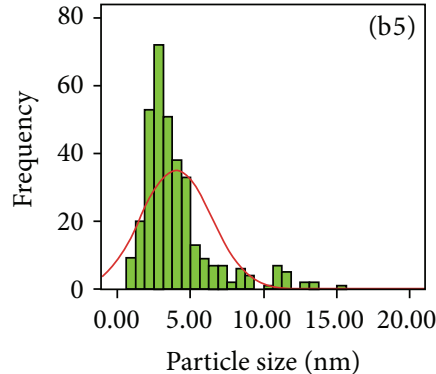

Number of particles: 342

Average of particle size: $4.01 \mathrm{~nm}$
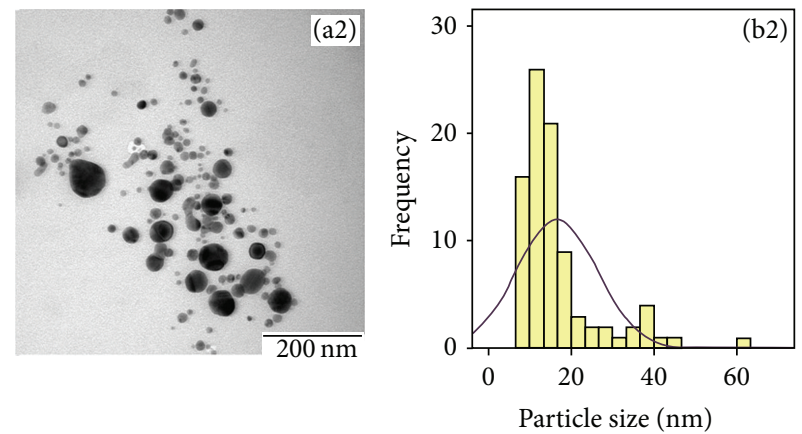

Number of particles: 89 Average of particle size: $18 \mathrm{~nm}$
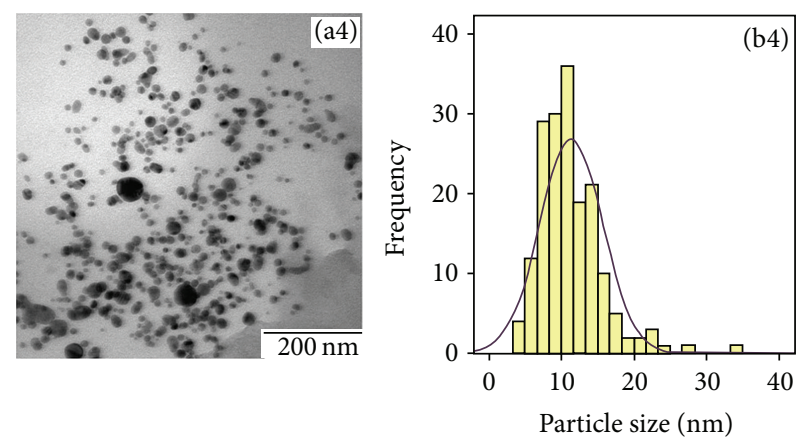

Number of particles: 176 Average of particle size: $11 \mathrm{~nm}$

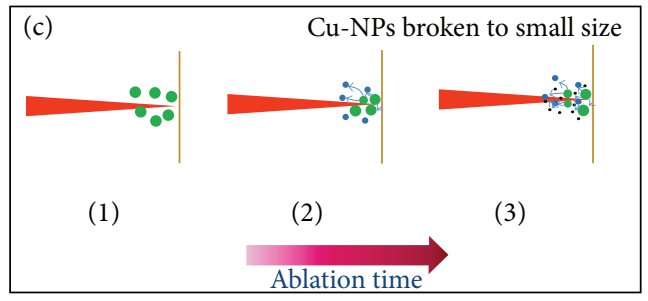

FIGURE 5: TEM images show the morphology, distribution, and particle size of $\mathrm{Cu}-\mathrm{NPs}$ in walnut oil with different ablation time. The Gaussian curves were fitted to the size bar chart and the particle size was in the range of $25 \mathrm{~nm}$ to $4.01 \mathrm{~nm}$. 
TABLE 1: The pertinent parameters of pure walnut oil and copper nanofluid.

\begin{tabular}{|c|c|c|c|c|c|c|c|}
\hline Sample & $\begin{array}{l}\text { Concentration } \\
\text { of } \\
\text { Cu-NPs (ppm) }\end{array}$ & $\begin{array}{l}\text { Volume fraction } \\
\qquad\left(\times 10^{-5}\right)\end{array}$ & $\begin{array}{l}\text { Average particle } \\
\text { size }(\mathrm{nm})\end{array}$ & $\begin{array}{l}\text { Real part of } \\
\text { refractive index } \\
(n)\end{array}$ & $\begin{array}{l}\text { Imaginary part of } \\
\text { refractive index } \\
(k)\end{array}$ & $\begin{array}{l}\text { Resonance } \\
\text { angle }\left(\theta_{R}\right)\end{array}$ & Reflectance \\
\hline Pure walnut oil & - & - & - & 1.4691 & 0.002 & $62.819^{\circ}$ & 0.0362 \\
\hline $5 \mathrm{~min}$ & 2.3 & 0.0257 & 25 & 1.4691 & 0.008 & $62.854^{\circ}$ & 0.0905 \\
\hline $10 \mathrm{~min}$ & 3.8 & 0.0424 & 17 & 1.4690 & 0.012 & $62.874^{\circ}$ & 0.1278 \\
\hline $20 \mathrm{~min}$ & 10.2 & 0.1138 & 15 & 1.4688 & 0.026 & $62.966^{\circ}$ & 0.2437 \\
\hline $30 \mathrm{~min}$ & 33.4 & 0.3728 & 11 & 1.4686 & 0.032 & $62.995^{\circ}$ & 0.2846 \\
\hline $50 \mathrm{~min}$ & 112.6 & 1.26 & 4.01 & 1.4682 & 0.043 & $63.042^{\circ}$ & 0.3455 \\
\hline
\end{tabular}

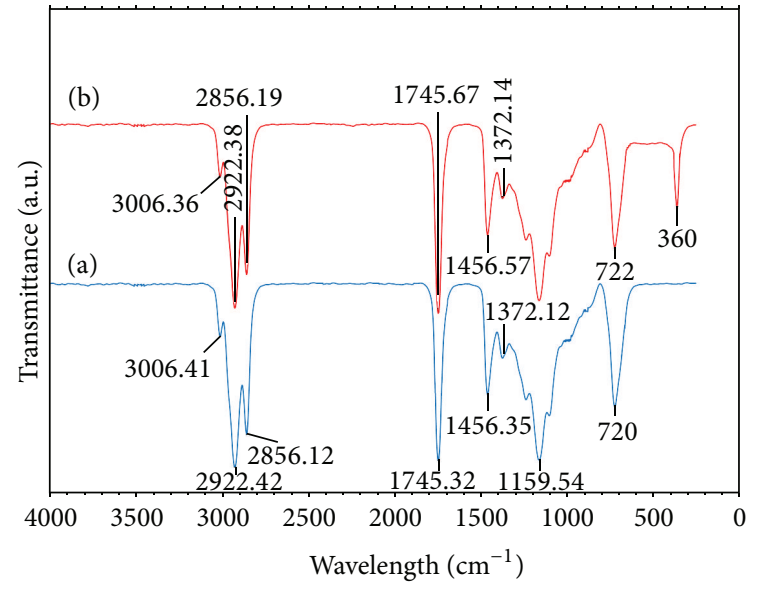

FIGURE 6: FT-IR results: (a) pure walnut oil, (b) walnut oil with $\mathrm{Cu}-$ NPs (nanofluid).

a wavelength ranging from $250 \mathrm{~cm}^{-1}$ to $4000 \mathrm{~cm}^{-1}$. The FTIR spectra are shown as a chemical structure before and after ablating the copper plate. Figure 6(a) shows the FTIR spectrum of the pure walnut oil where the peaks at $3006.41,2922.42,2856.12$, and $1745.32 \mathrm{~cm}^{-1}$ related to the $=\mathrm{C}-$ $\mathrm{H}$ stretching vibration, $\mathrm{CH}_{2}$ asymmetric, symmetric, and $\mathrm{C}=\mathrm{C}$ stretching ester carbonyl function group of triglycerides, respectively.

In addition, the peaks of $1456.35,1372.12,1159.54$, and $720 \mathrm{~cm}^{-1}$ corresponded to the $\mathrm{CH}_{2}$ bending, -C-O stretching vibration, and $-\mathrm{CH}_{2}$ bending (cis $-\mathrm{CH}=\mathrm{CH}$ - bending). The FT-IR spectrum after ablation of the copper plate is demonstrated in Figure 6(b). In the synthesis of Cu-NPs in walnut oil, the peaks at $3006.39,2922.38,1745.67,1456.57$, $1372.14,1158.87$, and $722.01 \mathrm{~cm}^{-1}$ confirm the stability of the molecular structure and functional groups. Also, the peaks appearing in $360 \mathrm{~cm}^{-1}$ are related to Cu-NPs [25]. The tail of the carbonyl band capped the $\mathrm{Cu}-\mathrm{NPs}$ through the electron transfer from the carboxylic group to Cu-NPs; as a result, the motion of molecules was impeded inside the particular area and the entropy decreased $[26,27]$. This proves that a long hydrocarbon chain prevents the agglomeration of Cu-NPs.

The SPR technique is a versatile method for measuring the real and imaginary parts of a nanofluid as it relies on the refractive index of the medium and the concentration of $\mathrm{Cu}-$ NPs in the walnut oil. Figure 7 shows the SPR signal for pure

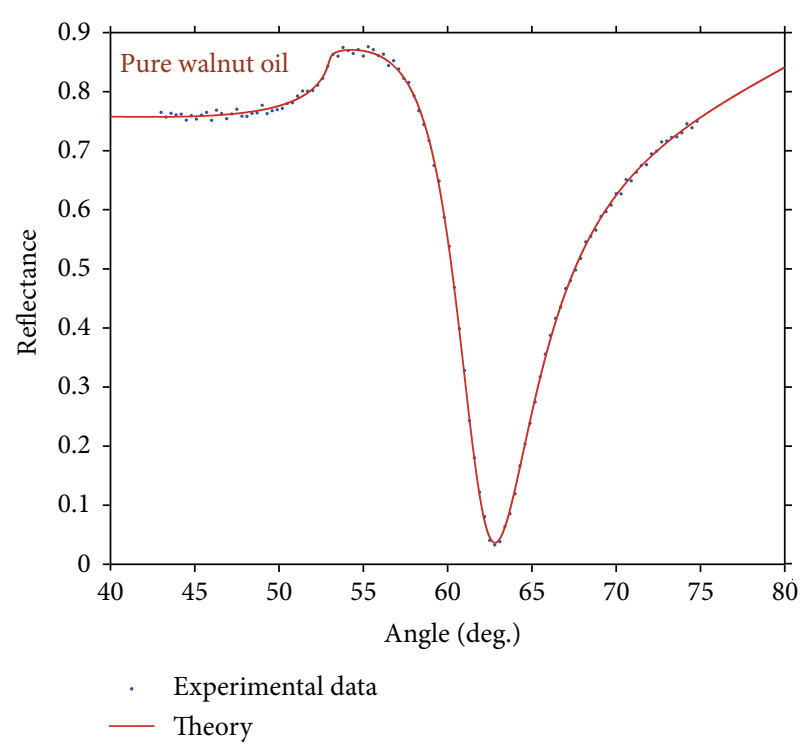

FIGURE 7: SPR signal related to pure walnut oil. The resonance angle is $62.819^{\circ}$ which corresponds to $1.4691+0.002 \mathrm{i}$ refractive index.

walnut oil where the resonance angle occurred at $62.819^{\circ}$, which is equivalent to the $1.4691+0.002 \mathrm{i}$ refractive index.

Figure 8 shows the relationship of the SPR and optical properties of the copper nanofluid. The resonance angle shifted from $62.854^{\circ}$ to $63.042^{\circ}$ and the reflectance increased as a result of an increase in the volume fraction of $\mathrm{Cu}-\mathrm{NPs}$. This is due to the increase in absorption and imaginary parts of the refractive index of the nanofluid.

Figures 9(a) and 9(b) show the variation of real and imaginary parts of refractive index of nanofluid. Consistent with the Kramers-Kroning relationship, the real part of the refractive index decreased as a consequence of an increase in the imaginary part [28]. The volume fraction of $\mathrm{Cu}-\mathrm{NPs}$ changed from $0.0257 \times 10^{-5}$ to $1.26 \times 10^{-5}$, so the scattering cross section of nanofluid increased (Figure 4(b)); therefore, the absorption and the imaginary part of nanofluid heightened. The experimental results are summarized in Table 1.

\section{Conclusion}

The $\mathrm{Cu}-\mathrm{NPs}$ were dispersed in walnut oil using laser ablation. The UV-visible peaks appeared at $615 \mathrm{~nm}, 606 \mathrm{~nm}, 588 \mathrm{~nm}$, 


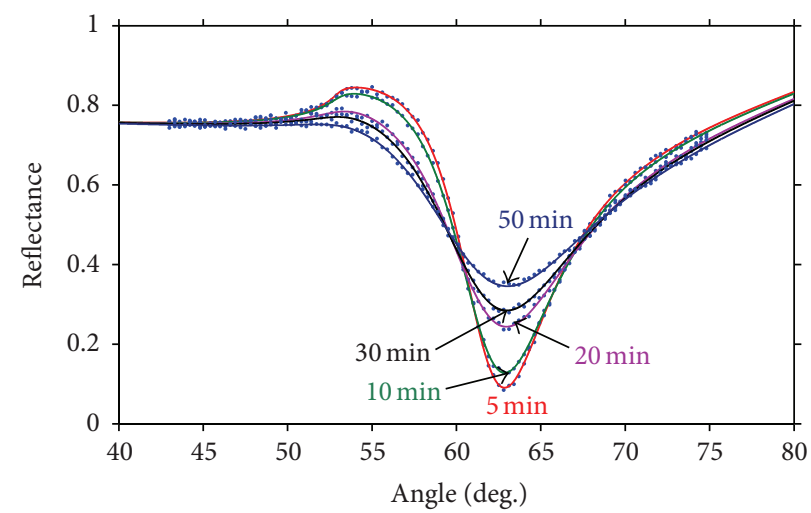

FIGURE 8: SPR signals for measurement of the refractive index of the nanofluid in different ablation time.

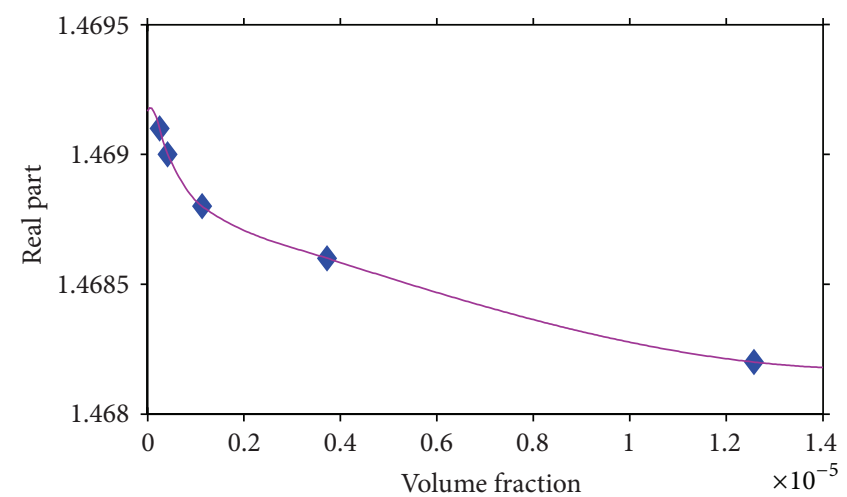

(a)

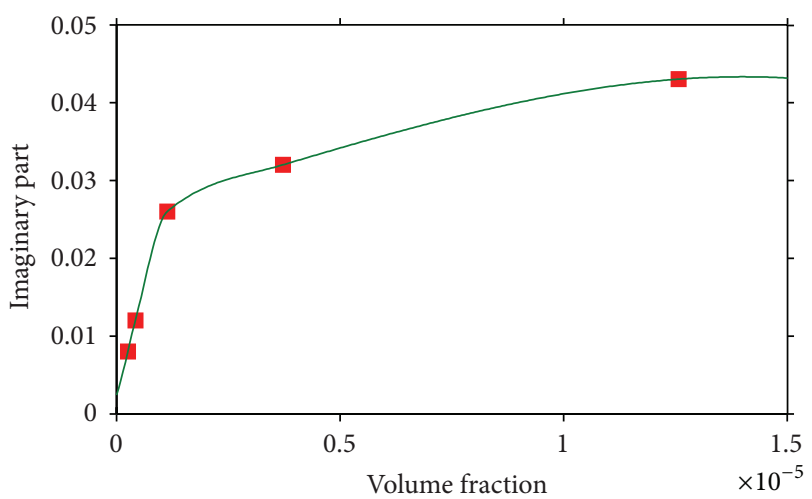

(b)

FIGURE 9: (a) The real part of refractive index decreased by increasing the volume fraction of nanofluid. (b) The imaginary part of refractive index increased by increasing the volume fraction of nanofluid.

$576 \mathrm{~nm}$, and $561 \mathrm{~nm}$, and particle size decreased from $25 \mathrm{~nm}$ to $4.01 \mathrm{~nm}$ in a spherical shape with an increase in the concentration of $\mathrm{Cu}-\mathrm{NPs}$ from 2.3 to $112.6 \mathrm{ppm}$. As in FTIR results, the tail of the carbonyl band capped the $\mathrm{Cu}$ NPs through the electron transfer from the carboxylic group to $\mathrm{Cu}-\mathrm{NPs}$. The refractive index was obtained using the SPR technique and shifted from $1.4691+0.008$ i to $1.4682+$ $0.043 \mathrm{i}$. The synthesis of $\mathrm{Cu}-\mathrm{NPs}$ did not require any agent or extra chemical component. Based on these characteristics, the laser ablation contributes as a green and suitable method to the preparation of $\mathrm{Cu}-\mathrm{NPs}$ in walnut oil. Therefore, the preparation of $\mathrm{Cu}-\mathrm{NPs}$ in walnut oil is suggested for future activity to prepare the skin cream or skin lotion, and the effect of particle size and concentration of particles in walnut oil are the objective in future research.

\section{Competing Interests}

The authors declare that they have no competing interests.

\section{Acknowledgments}

The authors acknowledge Universiti Putra Malaysia for the fund from the Research University Grant Scheme (Putra
Grant, Vote 941300) and the postdoctoral fellowship under the Institute of Advance Technology (ITMA).

\section{References}

[1] A. C. Templeton, W. P. Wuelfing, and R. W. Murray, "Monolayer-protected cluster molecules," Accounts of Chemical Research, vol. 33, no. 1, pp. 27-36, 2000.

[2] S. Chen and Y. Yang, "Magnetoelectrochemistry of gold nanoparticle quantized capacitance charging," Journal of the American Chemical Society, vol. 124, no. 19, pp. 5280-5281, 2002.

[3] L. A. Peyser, A. E. Vinson, A. P. Bartko, and R. M. Dickson, "Photoactivated fluorescence from individual silver nanoclusters," Science, vol. 291, no. 5501, pp. 103-106, 2001.

[4] D.-K. Kim, S. M. Yoo, T. J. Park et al., "Plasmonic properties of the multispot copper-capped nanoparticle array chip and its application to optical biosensors for pathogen detection of multiplex DNAs," Analytical Chemistry, vol. 83, no. 16, pp. 6215$6222,2011$.

[5] S. Giuffrida, L. L. Costanzo, G. Ventimiglia, and C. Bongiorno, "Photochemical synthesis of copper nanoparticles incorporated in poly(vinyl pyrrolidone)," Journal of Nanoparticle Research, vol. 10, no. 7, pp. 1183-1192, 2008.

[6] G. E. Jackson, L. Mkhonta-Gama, A. Voyé, and M. Kelly, "Design of copper-based anti-inflammatory drugs," Journal of Inorganic Biochemistry, vol. 79, no. 1-4, pp. 147-152, 2000. 
[7] D. Deng, Y. Cheng, Y. Jin, T. Qi, and F. Xiao, "Antioxidative effect of lactic acid-stabilized copper nanoparticles prepared in aqueous solution," Journal of Materials Chemistry, vol. 22, no. 45, pp. 23989-23995, 2012.

[8] M. J. F.-A. Tuorkey and K. K. Abdul-Aziz, "A pioneer study on the anti-ulcer activities of copper nicotinate complex $[\mathrm{CuCl}$ (HNA)2] in experimental gastric ulcer induced by aspirinpyloris ligation model (Shay model)," Biomedicine and Pharmacotherapy, vol. 63, no. 3, pp. 194-201, 2009.

[9] M. D. Bilgin, A. E. Elçin, and Y. M. Elçin, "Topical use of liposomal copper palmitate formulation blocks porphyrininduced photosensitivity in rats," Journal of Photochemistry and Photobiology B: Biology, vol. 80, no. 2, pp. 107-114, 2005.

[10] P. Raveendran, J. Fu, and S. L. Wallen, "Completely 'Green' synthesis and stabilization of metal nanoparticles," Journal of the American Chemical Society, vol. 125, no. 46, pp.13940-13941, 2003.

[11] S. Giuffrida, G. G. Condorelli, L. L. Costanzo, I. L. Fragala, G. Ventimiglia, and G. Vecchio, "Photochemical mechanism of the formation of nanometer-sized copper by UV irradiation of ethanol Bis(2,4-pentandionato) copper(II) solutions," Chemistry of Materials, vol. 16, no. 7, pp. 1260-1266, 2004.

[12] L.-P. Jiang, A.-N. Wang, Y. Zhao, J.-R. Zhang, and J.-J. Zhu, "A novel route for the preparation of monodisperse silver nanoparticles via a pulsed sonoelectrochemical technique," Inorganic Chemistry Communications, vol. 7, no. 4, pp. 506-509, 2004.

[13] I. Haas, S. Shanmugam, and A. Gedanken, "Pulsed sonoelectrochemical synthesis of size-controlled copper nanoparticles stabilized by poly(N-vinylpyrrolidone)," The Journal of Physical Chemistry B, vol. 110, no. 34, pp. 16947-16952, 2006.

[14] A. R. Sadrolhosseini, A. S. B. M. Noor, K. Shameli, G. Mamdoohi, M. M. Moksin, and M. A. Mahdi, "Laser ablation synthesis and optical properties of copper nanoparticles," Journal of Materials Research, vol. 28, no. 18, pp. 2629-2636, 2013.

[15] R. K. Swarnkar, S. C. Singh, and R. Gopal, "Effect of aging on copper nanoparticles synthesized by pulsed laser ablation in water: structural and optical characterizations," Bulletin of Materials Science, vol. 34, no. 7, pp. 1363-1369, 2011.

[16] S. Hamad, G. K. Podagatlapalli, S. P. Tewari, and S. V. Rao, "Influence of picosecond multiple/single line ablation on copper nanoparticles fabricated for surface enhanced Raman spectroscopy and photonics applications," Journal of Physics D: Applied Physics, vol. 46, no. 48, Article ID 485501, 2013.

[17] M. Muniz-Miranda, C. Gellini, and E. Giorgetti, "Surfaceenhanced Raman scattering from copper nanoparticles obtained by laser ablation," Journal of Physical Chemistry C, vol. 115, no. 12, pp. 5021-5027, 2011.

[18] L. D. McKay and D. Sibley, "Omega-3 fatty acids," 2014, http://www.nutritiondimension.com/.

[19] L. Thomas, “Article Source," 2009, http://EzineArticles.com/ 2675999.

[20] J. Homola, Surface Plasmon Resonance Based Sensors, Springer, Berlin, Germany, 2001.

[21] N. Peyghambarian, S. W. Koch, and A. Mysyrowic, Introduction to Semiconductor Optics, Prentice Hall, Upper Saddle River, NJ, USA, 1993.

[22] A. J. Jääskeläinen, K.-E. Peiponen, and J. A. Räty, "On reflectometric measurement of a refractive index of milk," Journal of Dairy Science, vol. 84, no. 1, pp. 38-43, 2001.

[23] A. R. Sadrolhosseini, M. M. Moksin, W. M. M. Yunus, Z. A. Talib, and M. M. Abdi, "Surface plasmon resonance detection of copper corrosion in biodiesel using polypyrrole-chitosan layer sensor," Optical Review, vol. 18, no. 4, pp. 331-337, 2011.

[24] G. Yang, Laser Ablation in Liquids, Pan Stanford, Singapore, 2012.

[25] M. S. Usman, M. E. El Zowalaty, K. Shameli, N. Zainuddin, M. Salama, and N. A. Ibrahim, "Synthesis, characterization, and antimicrobial properties of copper nanoparticles," International Journal of Nanomedicine, vol. 8, pp. 4467-4479, 2013.

[26] L. Qiu, F. Liu, L. Zhao, W. Yang, and J. Yao, "Evidence of a unique electron donor-acceptor property for platinum nanoparticles as studied by XPS," Langmuir, vol. 22, no. 10, pp. 4480-4482, 2006.

[27] A. I. Roucoux, J. Schulz, and H. Patin, "Reduced transition metal colloids: a novel family of reusable catalysts?" Chemical Reviews, vol. 102, no. 10, pp. 3757-3778, 2002.

[28] F. S. Damos, R. C. S. Luz, and L. T. Kubota, "Investigations of ultrathin polypyrrole films: formation and effects of doping/dedoping processes on its optical properties by electrochemical surface plasmon resonance (ESPR)," Electrochimica Acta, vol. 51, no. 7, pp. 1304-1312, 2006. 

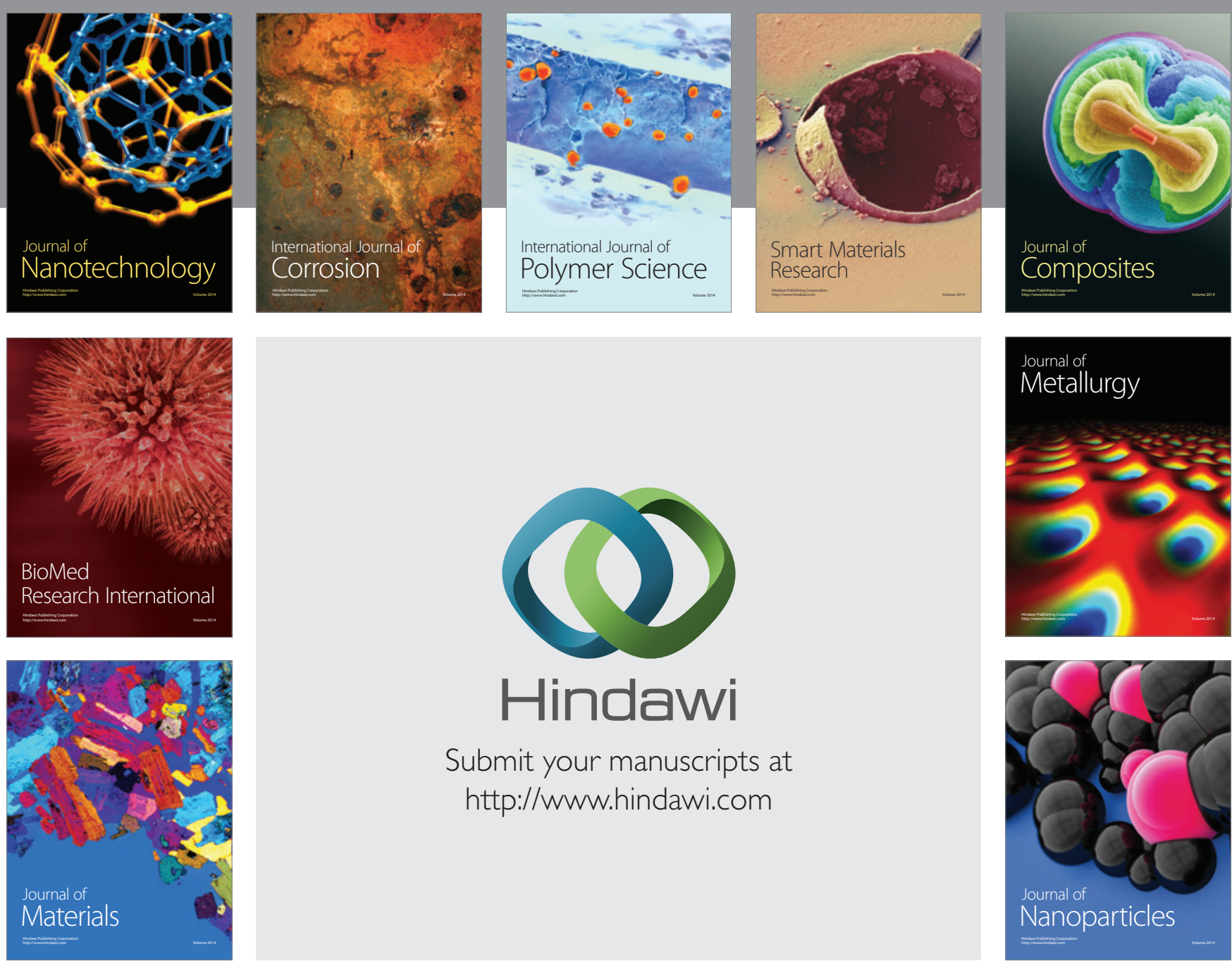

\section{Hindawi}

Submit your manuscripts at

http://www.hindawi.com

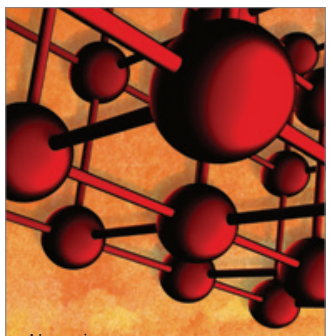

Materials Science and Engineering
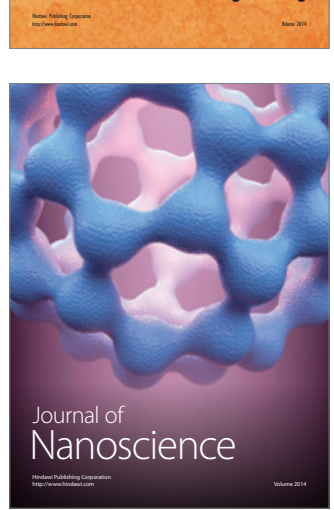
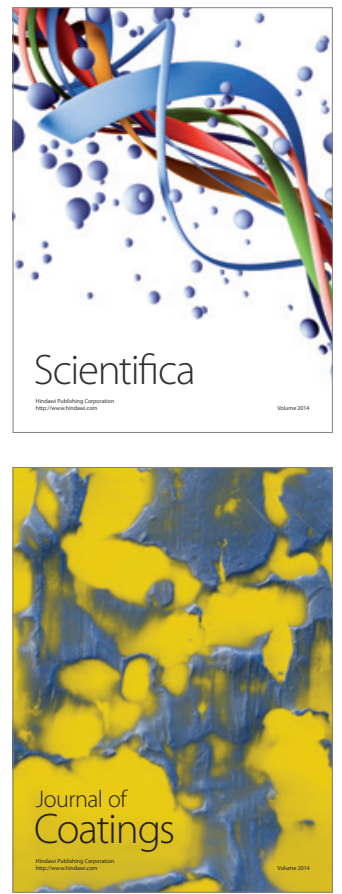
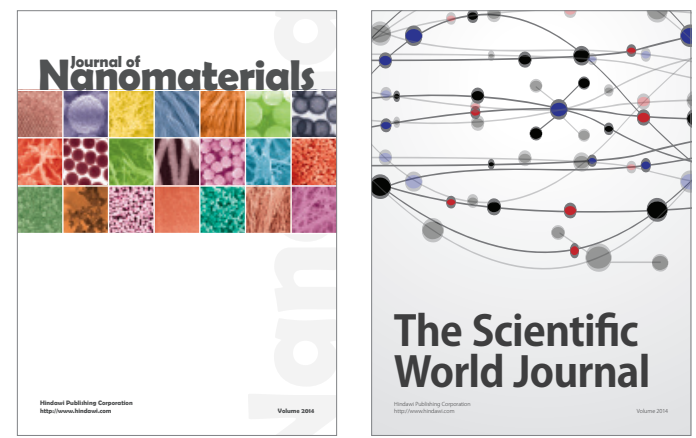

The Scientific World Journal
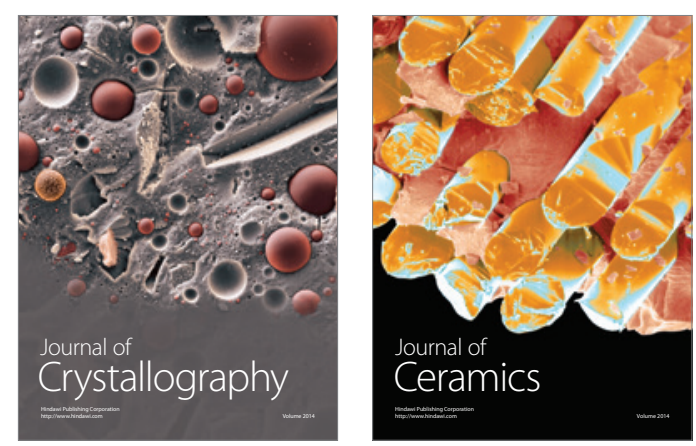
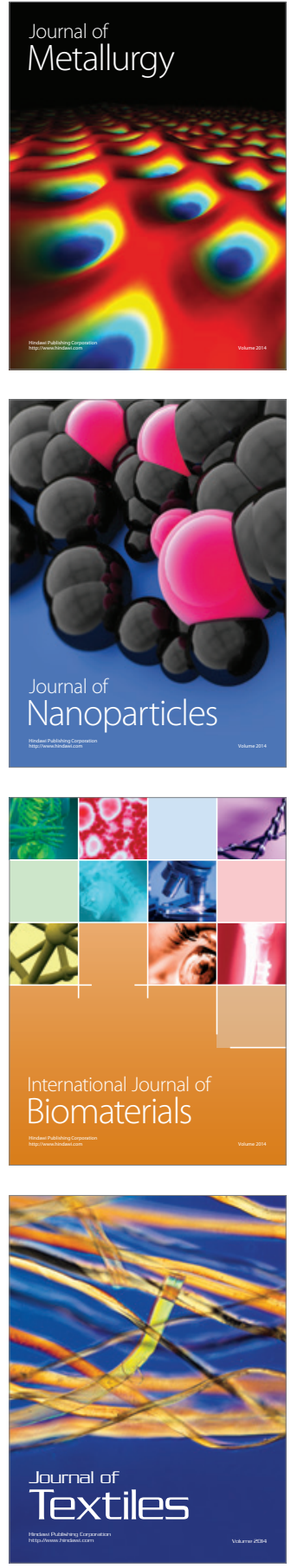